\title{
Laboratory Activity Using Rapid Prototyping and Casting
}

\author{
Richard Griffin, Terry Creasy, and Jeremy Weinstein \\ MEEN Dept. 3123, Texas A\&M University, College Station, TX 77843-3123
}

\begin{abstract}
Mechanical Engineering at Texas A\&M University has been undergoing a curriculum revision in an effort to reduce the total number of hours that are required for a Bachelor of Science Degree. As part of the development, a two sequence course-materials and manufacturing processes have been combined into one course. This past fall, the course was taught for the first time to multiple sections.

Both of the prior courses had laboratory components, and the new materials/manufacturing course has been developing a set of laboratory activities that combine both topics. The experiment to be described in this paper involves the rapid prototyping of a component, using that part as a mold for an aluminum casting, and finally the evaluation of the part. The experiment is performed over a several week period. The students design a small part using a solids modeling program (Currently, MEEN is using Solid Works.); the part is then used as a mold for a green sand aluminum casting. The part is constrained by the volume of the rapid prototyping machine and the ability to make a mold for casting. The students must evaluate the results to see if it meets their objective as set out during the initial design phase.

One of our goals with the new laboratory activities is to provide opportunities for students to make as many decisions in the conduction of the laboratory as is practical. This activity allows the students to design the part and evaluate the results of the cast part. Examples of student work will be discussed.
\end{abstract}

\section{Introduction}

As part of a curriculum revision in Mechanical Engineering at Texas A\&M University, College Station, TX properties of materials and manufacturing processes courses have been combined into one course. At the 2001 ASEE meeting we reported the process used to develop the new course, and briefly discussed the laboratory activities that were being developed. ${ }^{1}$ One of our goals in developing the new course was to provide laboratory activities that allow the students to make choices in the development of the laboratory, and see the results of their choices. ${ }^{2,3,4}$ This paper will describe a laboratory activity that involves the design, rapid prototyping, casting and evaluation of a part.

"Proceedings of the 2002 American Society for Engineering Education Annual Conference \& Exposition Copyright (C) 2002, American Society for Engineering Education. 


\section{Procedure}

The students have two weeks to run this experiment plus development time for the solid model. The description will be separated into four parts: solid modeling, rapid prototyping, casting, and evaluation.

Solid Modeling- Students are asked to develop two solid models. One for a tensile specimen that is to be machined by a CNC machine, and two for a part to be made by a selective laser sintering (SLS) process and then cast in aluminum. The CNC machine had a workspace size of $120 \times 100$ x $120 \mathrm{~mm}$, and the part was to be made from acrylic. Figure 1 shows an example of the solid model for the tensile specimen. The second part was to be a gear blank that had the following constraints: maximum diameter was $240 \mathrm{~mm}$, gear thickness was a maximum of $24 \mathrm{~mm}$, and the hub must be no thicker than $48 \mathrm{~mm}$ with a diameter of $80 \mathrm{~mm}$. See Figure 2 for a schematic of the component.

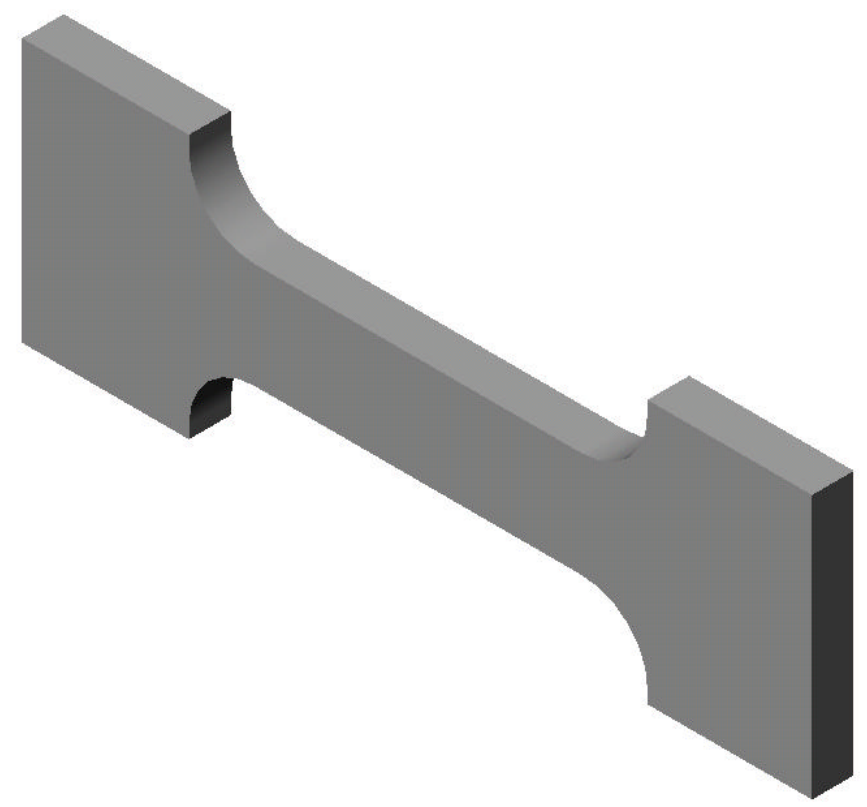

Figure 1. Tensile specimen designed as a solid model and manufactured using a CNC machine.

Rapid Prototyping- Two methods were used. The first was to use a CNC machine to produce one component. The second was to use SLS* to prepare a mold for a sand casting. Both systems were able to directly use the solid modeling files (.STL) and produce the particular part.

*Since the paper was prepared, the Mechanical Engineering Department has purchased a rapid prototyping machine that uses 3-D printing technology and a powder (starch) with a binder to produce the models.

Figure 2 shows an example of the gear blank that the students designed. The finished product is shown in Figure 3a, while the gates and runners are shown in Figure $3 b$. 
Casting- the components are produced by green sand casting, and cast in aluminum. An example of the finished mold after pouring is shown in Figure 4.

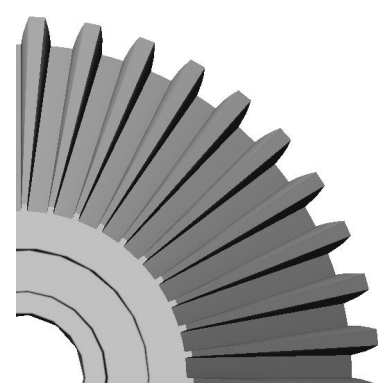

a)

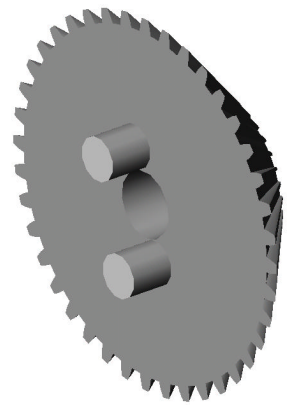

b)

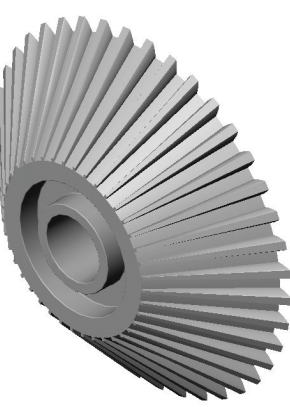

c)

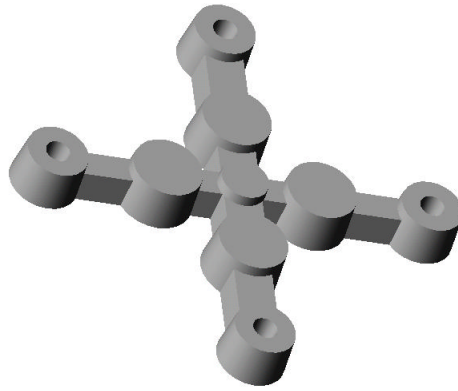

d)

Figure 2. Solidworks models. a) Detail of bevel gear, b) Mounting pins integrated with blank, c) Isometric view of the gear, d) Gates and runners.
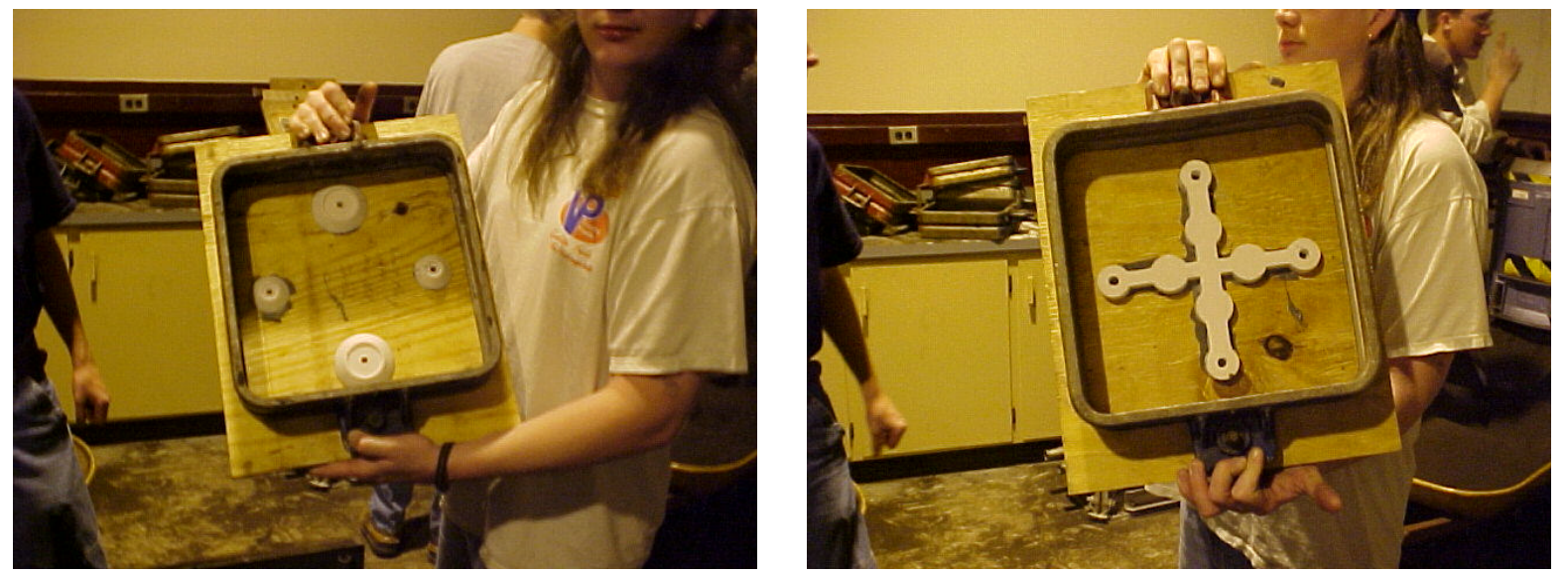

Figure 3. a. Gears. b. Gates and runners.

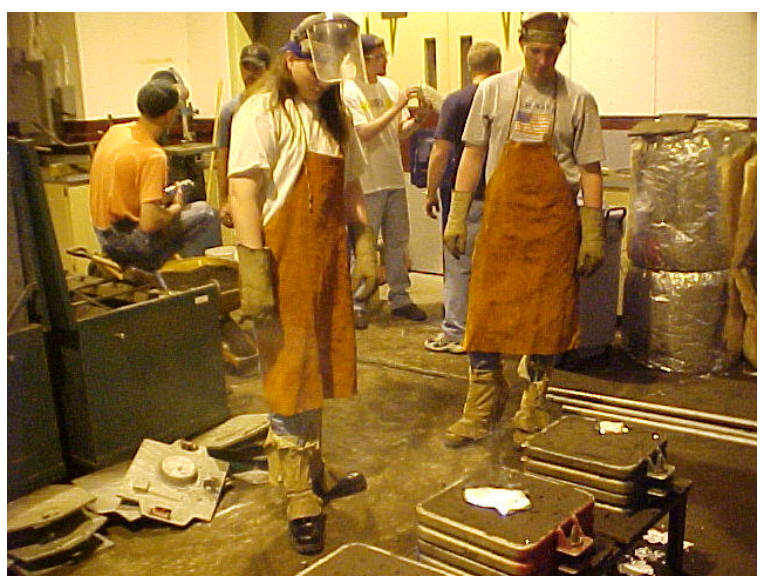

Figure 4. Castings after pouring.

"Proceedings of the 2002 American Society for Engineering Education Annual Conference \& Exposition Copyright (c) 2002, American Society for Engineering Education. 
Evaluation- After pouring and shaking out the castings, the students are required to evaluate their products. Does it meet the specifications? Are the dimensions satisfactory? Etc.

\section{Observations}

During the laboratory activity, the students have the opportunity to develop and observe two types of rapid prototyping operations. The $\mathrm{CNC}$ machine is used to produce a tensile specimen, while the SLS System uses laser technology and powder to make components. The tensile specimens were tested in a uniaxial testing machine. The parts produced in the SLS machine were used as the molds for making an aluminum casting.

It was not as easy for the students to make the solid model as we had anticipated. In fact, as Figure 3a shows, the gears became more of a bevel gear. We also had some difficulties with pulling the molds from the sand, and we had to be careful of the draft angles that were used. Overall, it was our opinion that the activity was successful in demonstrating the interplay of solid modeling-rapid prototyping-and casting.

Further developments are necessary in the use and application of solid modeling. For the activity described in this paper, a SLS system was used to make the molds. The system was quite slow and cumbersome to use. Currently, mechanical engineering is in the process of using a newer 3D printing technology machine that uses starch to produce the components. This will make the parts less expensively and faster. The new machine has a $10 \times 8 \times 10$ " part size, and therefore, we need to rethink our original design constraints.

Additionally, it would be beneficial for the students to be able to rapid prototype the same component by $\mathrm{CNC}$ and powder processing. The current limit is the size of the CNC machine that is available for laboratory use. A proposal has been written and is in the process of being evaluated that would enable us to rapid prototype larger parts and thus the same component could be made by CNC and powder processing methods.

\section{Conclusions}

A multipart experiment has been developed and implemented that involves solid modeling, rapid prototyping, $\mathrm{CNC}$ machining, and casting. The students design a part, rapid prototype it, and make it by casting and $\mathrm{CNC}$ machining. ${ }^{5}$ 
${ }^{1}$ Richard B. Griffin, Terry S. Creasy The Development of a Combined Materials/Manufacturing Processes Course at Texas A\&M University, ASEE 2001, Albuquerque, NM, Session 2464, June 2001.

${ }^{2}$ R. B. Griffin, K. T. Hartwig, R. Barber, T. New, and I. Karaman, "Development of a Deformation Processing laboratory," National Educators Workshop New: Update 2001, Oct. 2001, College park, MD.

${ }^{3}$ S. Palmer Engineering Flexible Teaching And Learning In Engineering Education, European Journal of Engineering Education, 2001, 261 pp1-13

${ }^{4}$ N. J. Buch and T. F. Wolff, Classroom Teaching Through Inquiry, Journal of Professional Issues in Engineering Education and Practice, 2000, 1263 pp. 105-109

${ }^{5}$ M. S. Tavakoli and J. Mariappan, Concurrent Teaching of Engineering Design, Analysis and Manufacturing, International Journal of Mechanical Engineering Education, 2000, 284 pp. 321-333

RICHARD B. GRIFFIN- Dr. Griffin has been at Texas A\&M University since 1977. He has been an active member of the Foundation Coalition and regularly presented papers on work done. His other active area is corrosion where for the past several years he has been working on the corrosion of metals under organic coatings.

TERRY S. CREASY- Dr. Creasy joined Texas A\&M University in August of 2000. He has 8.5 years of industrial experience in the aerospace field and performs research in the areas of properties and processing composite and polymer materials.

JEREMY WEINSTEIN- Mr. Weinstein is a graduate student in mechanical engineering at Texas A\&M University. He has several years of industrial experience as a designer. His thesis topic is related to the development of laboratory activities.

"Proceedings of the 2002 American Society for Engineering Education Annual Conference \& Exposition Copyright (c) 2002, American Society for Engineering Education. 